\title{
Pengaruh Doping Kromium (Cr) Terhadap Sifat Kekerasan Pada Pembuatan Roda Gigi Lurus Berbahan Serbuk Besi (Fe)
}

\author{
Albert Daniel Saragih', ${ }^{1}$, Slamet Sutjipto's) \\ ${ }^{1,2)}$ Teknik Mesin, Politeknik Negeri Bandung, Bandung 40012, Indonesia \\ www.polban.ac.id ${ }_{2}$ albertdanielsrgh@polban.ac.id
}

\begin{abstract}
Abstrak - Roda gigi adalah bagian dari mesin yang memiliki bentuk sangat kompleks sehingga diperlukan ketelitian dan keahlian khusus didalam proses pembuatannya. Metalurgi serbuk menawarkan suatu proses pembuatan yang efisien guna menghasilkan bagian-bagian permesinan yang kompleks tersebut. Pada penelitian ini dipilih serbuk logam Cr untuk meningkatkan sifat kekerasan dari roda gigi lurus berbahan dasar serbuk besi (Fe). Doping $\mathrm{Cr}$ sebesar 0\%; 0,5\%; 10\%, 1,5\% dan 2,0\% akan ditambahakan pada pembuatan roda gigi. Air digunakan sebagai pengikat dengan ratio 1:15 yang selanjutnya dikompaksi sebesar 15,000 kg atau 15 ton diteruskan dengan dipanaskan atau sintering pada suhu 1200 oC selama 1 jam. Ratio penyusutan sampel terhadap perlakuan sintering rata-rata $4.6 \%$. Sebesar $0.2 \mathrm{~kg}$ beban yang terapkan pada pengujian kekerasan Vickers. Nilai kekerasan Vickers diperoleh sebesar 60, 77, 90, 184 dan 211 masing-masing untuk doping Cr sebesar 0\%; 0,5\%; 10\%, 1,5\% dan 2,0\%. Dari data tersebut didapat bahwa penambahan unsur Cr meingkatkan sifat kekerasan pada roda gigi besi. Nilai kekerasan yang ditunjukkan masih terlalu kecil hal ini disebabkan oleh masih banyak porositas yang ditimbulkan pada proses sintering karena tidak dalam kondisi vakum.
\end{abstract}

Kata kunci: roda gigi, kromium, doping, sintering.

\begin{abstract}
Gear is a part of a machine that has a very complex shape that requires a special care and expertise in the manufacturing process. Powder metallurgy offers an efficient manufacturing process for the production of these complex machining parts. In this study, Cr metal powders was selected to improve the hardness properties of spurt gears that made from iron ( $\mathrm{Fe}$ ) powder. Cr doped percentages of 0.5, 1, 1.5, and $2 \%$ will doped to the manufacture of spur gears. Water is used as a binder with a ratio of 1:15 and compacted of $15,000 \mathrm{~kg}$ followed by sintering at $1200{ }^{\circ} \mathrm{C}$ for 1 hour. The average shrinkage ratio of the sample after the sintering treatment was $4.6 \% .0 .2 \mathrm{~kg}$ of load applied to the Vickers hardness test. The Vickers hardness values were 63, 75, 96, 185 and 207 for $\mathrm{Cr}$ doping of 0, 0.5, 1, 1.5, and 2\%, respectively. From these data it is found that the doping $\mathrm{Cr}$ increase the hardness properties of iron gears. The hardness value shown is still too small, this is due to the large amount of porosity generated in the sintering process because it is not in a vacuum condition.
\end{abstract}

Keyword: Gears, Chrom, doping, sintering

\section{PENDAHULUAN}

Roda gigi adalah salah satu bagian dari mesin yang paling sering digunakan. Roda gigi ini berfungsi untuk mentransmisikan energi/daya dari satu bagian mesin ke bagian yang lainnya. Ada beberapa jenis roda gigi, roda gigi lurus adalah salah satu jenis roda gigi yang paling banyak digunakan.

Berbagai cara dapat digunakan untuk membuat atau memproduksi roda gigi, diantaranya adalah proses pengecoran (casting), tempa (forging), ekstruksi, dan metalurgi serbuk. Masing-masing proses diatas memiliki keunggulan dan kelemahannya masing-masing. Adapun pasar utama dari metalurgi serbuk adalah sektor otomotif. Rata-rata disemua wilayah sekitar $80 \%$ dari semua komponen metalurgi serbuk adalah untuk industri otomotif [1]. Dapat memproduksi bentuk yang sangat kompleks adalah satu kelebihan dari proses metalurgi serbuk, misalnya adalah roda gigi, poros dan sebagainya. Metalurgi serbuk seringkali dimungkinkan untuk menghasilkan bagian-bagian yang tidak dapat dikerjakan secara ekonomis, seperti proses pengecoran [2].

Berbagai usaha telah dilakukan dalam pembuatan roda gigi dengan menggunakan proses metalurgi serbuk. M.S. Yafie dkk [3] telah melakukan penelitian terhadapa pengaruh pengaruh variasi temperatur sintering dan waktu tahan sintering terhadap densitas dan kekerasan pada $\mathrm{Mmc} \mathrm{W}-\mathrm{Cu}$ dengan menggunakan metode metalurgi serbuk. Pembuatan material proyektil dengan komposisi fraksi berat $70 \% \mathrm{~W}$ dan 
$30 \% \mathrm{Cu}$ dengan tekanan kompaksi $400 \mathrm{MPa}$ diterapkan pada penelitian tersebut. Dengan temperatur sintering terbaik sebesar $900 \mathrm{oC}$ diperoleh nilai kekerasan sebesar 34,7 $\mathrm{HRb}$ dengan penahanan selama 2 jam. A. S. Fauzi, dkk [4] didalam penelitiannya telah membuat roda gigi dari bahan serbuk logam tembaga dan alumunium. Dengan menggunakan proses kompaksi, green compact (GC) di tekan dengan kekuatan 6 ton kemudian disinter pada suhu 868 oC. Hasil terbaik diperoleh dengan komposisi tembaga $75 \%$ dan alumunium sebanyak $25 \%$. Namun, hasil kekerasan yang diperoleh belum mencapai nilai yang diinginkan. X. Li, dkk pada tahun 2015 [5] melaporkan hasil penelitiannya dalam pembuatan roda gigi dengan menggunakan teknik metalurgi serbuk. Penambahan unsur Ni, C, dan Mo diberikan kepada dominan logam serbuk besi. Sampel kemudian di sinter pada suhu 1120 oC selama 45 menit pada kondisi vakum. Modulus Young's yang dihasilkan dari proses ini masih lebih kecil dari proses konvensional.

Selain menjadi penelitian yang baru, pemilihan unsur kromium dipilih karena sifatnya yang tidak mudah teroksidasi oleh udara, oleh karena itu banyak digunakan sebagai pelapis logam, pengisi stainless steel, lapisan perlindungan untuk mesin-mesin otomotif dan perlengkapan tertentu [6]. Sehingga didalam penelitian dipilih logam $\mathrm{Cr}$ agar dapat memberikan dampak yang baik pada pembuatan roda gigi lurus khususnya sifat kekerasannya.

\section{LANDASAN TEORI}

Rancang bangun pembuatan cetakan/dies roda gigi lurus telah dikerjakan oleh mahasiswa jurusan teknik mesin ditahun 2013. Tugas Akhir dengan judul "Rancang Bangun Cetakan Roda Gigi Lurus Berbasis Metalurgi Serbuk Tanpa Lubang Poros" tersebut dikerjakan oleh Muhammad Iqbal Zulkarnain dan Riki Nopiandi [7]. Gambar 1 menunjukan alat cetak untuk membuat roda gigi lurus dengan metode kompaksi.

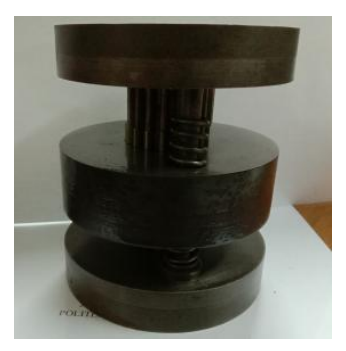

Gambar 1. Alat cetak roda gigi lurus dengan menggunakan metode kompaksi.
Sekitar $80 \%$ dari semua serbuk metal dihasilkan dari proses atomisasi, dimana bahan cair didisintegrasi menjadi tetesan kecil yang dingin dan mengeras menjadi partikel [2]. Seperti yang kita ketahui bahwa urutan proses metalurgi terdiri dari 3 tahapan, yaitu: (1) pengadukan atau pencampuran serbuk logam. Proses pengadukan atau pencampuran serbuk dapat dilakukan dengan metode kering atau metode basah, di mana air atau larutan lainnya digunakan untuk meningkatkan mobilitas partikel, mengurangi pembentukan debu, dan mengurangi bahaya ledakan ketika pemandatan berlangsung. (2) Kompaksi atau pemandatan, dimana serbuk ditekan sesuai dengan bentuk yang diinginkan. Salah satu langkah paling kritis dalam proses metalurgi serbuk adalah pemadatan. Serbuk logam dikompres/ditekan dan dipadatkan menjadi bentuk yang dikenal sebagai kompaksi hijau (green compact/GC), pada umumnya dilakukakan pada suhu kamar. Kepadatan produk yang tinggi dan keseragaman dari kerapatan tersebut di seluruh sampel umumnya merupakan karakteristik yang diinginkan yang untuk selanjutkan dilakukan proses pemanasan atau sintering. Tekanan yang diterapkan dalam pada proses juga dapat menghilangkan penghubung yang terbentuk selama pengisian serbuk kedalam cetakan/dies, mengurangi ruang pori, dan meningkatkan jumlah titik kontak antara partikel-partikel serbuk logam. Secara umum proses pemadatan banyak dilakukan dengan pengepres mekanis/konvensional dengan mesin press dan ada juga menggunakan mesin tekan hidrolik maupun mesin press pneumatik. Kapasitas tekanan untuk produksi metalurgi serbuk umumnya diberikan dalam ton atau $\mathrm{kN}$ atau MN. Gaya (F) yang diperlukan untuk pengepresan tergantung pada area yang diproyeksikan dari bagian metalurgi serbuk (area dalam bidang horizontal untuk pengepres vertikal yang disimbolkan dengan A) dikalikan dengan tekanan (p) yang dibutuhkan untuk memadatkan serbuk logam yang diberikan (persamaan (1)) [8].

$$
\mathrm{F}=A_{p} p_{c}
$$

Besarannya gaya kompaksi yang diberikan bervariasi bergantung pada material logam serbuk dan aplikasi produk seperti yang tertera pada Tabel 1 .

Tabel 1. Pembagian tekanan kompaksi untuk berbagai jenis aplikasi produk. [2] 


\begin{tabular}{|l|c|c|}
\hline \multirow{2}{*}{\multicolumn{1}{|c|}{ Aplikasi }} & \multicolumn{2}{c|}{ Tekanan Kompaksi } \\
\cline { 2 - 3 } & Ton/in ${ }^{2}$ & MPa \\
\hline Logam berongga dan penyaring & $3-5$ & $40-70$ \\
\hline Logam keras dan karbida & $5-15$ & $70-200$ \\
\hline Bantalan (bearing) berongga & $10-25$ & $146-35$ \\
& & 0 \\
\hline $\begin{array}{l}\text { Bagian-bagian mesin (densitas menengah, besi } \\
\text { dan baja) }\end{array}$ & $20-50$ & $275-69$ \\
\hline $\begin{array}{l}\text { Densitas Tinggi (Tembaga dan sebagaian } \\
\text { Alumunium) }\end{array}$ & $18-20$ & $\begin{array}{c}250-27 \\
5\end{array}$ \\
\hline Densitas Tinggi (besi dan sebagian baja) & $50-120$ & $690-16$ \\
& & 50 \\
\hline
\end{tabular}

(3) Sintering, yang melibatkan pemanasan pada suhu di bawah titik leleh untuk menghasilkan ikatan kondisi padat (solid-state) partikel dan dan memperkuat sampel. Sintering adalah suatu proses perlakuan panas yang dilakukan pada sampel atau GC untuk agar partikel logam saling berikatan sehingga meningkatkan kekuatan dan kekerasan sampel. Perlakuan panas biasanya dilakukan pada suhu antara 0,7 dan 0,9 titik leleh logam (pada skala absolut). Istilah sintering keadaan padat atau sintering fase padat kadang-kadang digunakan untuk sintering konvensional karena material logam tetap tidak meleleh pada suhu perlakuan ini [8].

\section{METODOLOGI PENELITIAN}
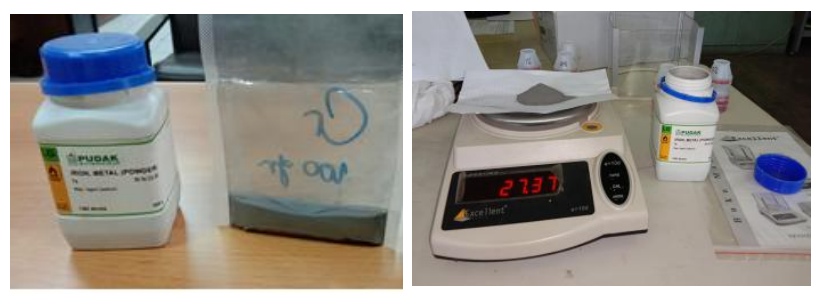

Gambar 2. Bahan penelitian yaitu serbuk besi dan serbuk krom (kiri), proses penimbangan bahan penelitian (kanan).

Serbuk Cr ditambahkan sebesar 0,5\%; 1,0\%; 1,5\% dan $2,0 \%$ pada pembuatan roda gigi lurus berbahan dasar serbuk besi (gambar 2). Seluruh material serbuk dicampur dengan menggunakan mesin pencampur konvesional selama 12 jam. Sebelum dikompaksi seluruh sampel yang sudah dicampur dengan berbagai variasi konsentrasi doping dicampur dengan dengan air. Air berfungsi sebagai pengikat/binder ditambahkan dengan ratio 1:15 terhadap serbuk material yang akan dicetak. Selanjutnya sampel dimasukkan kedalam cetakan (gambar 1). Dengan menggunakan kompaksi pada suhu ruangan, semua sampel akan dikompaksi dengan besaran 15 ton (gambar 3). Selanjutnya dilakukan sintering pada tungku pemanas/furnace dengan temperatur $1200{ }^{\circ} \mathrm{C}$ ditahan selama 1 jam.

Setelah proses sintering dilakukan, kemudian dilanjutkan ke tahap evaluasi sampel. Dalam hal ini direncanakan akan dilakukan perhitungan penyusutan serta pengujian sifat mekanik meliputi kekerasan dan metalografi, baik struktur dan komposisi unsur yang terkandung didalam roda gigi lurus. Rasio penyusutan ketebalan sampel setelah proses perlakuan panas atau sintering dihitung menggunakan persamaan teoretis (persamaan (2)), dimana $\mathrm{T}_{\mathrm{B}}$ adalah tebal sebelum sintering dan $\mathrm{T}_{\mathrm{A}}$ adalah tebal setelah sintering.

$$
\mathrm{S}_{\mathrm{r}}=\frac{T_{B}-T_{A}}{T_{B}} \times 100 \%
$$
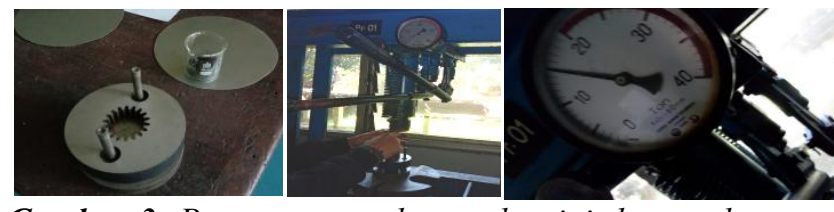

Gambar 3. Proses pencetakan roda gigi dengan besaran kompaksi 15 ton.

Pengujian sifat kekerasan roda gigi lurus dilakukan dengan metode mikro vickers (HM-122 Mitutoyo) menggunakan indentor intan yang dasarnya berbentuk bujur sangkar dengan sudut permukaan piramid yang berhadapan sebesar $136^{\circ}$. Pengujian dengan menggunakan SEM-EDS dan mikroskop optik (Olympus DP22, Japan) digunakan untuk menganalisis struktur morfologi dan persentase komposisi material yang terkandung pada roda gigi lurus.

\section{HASIL DAN PEMBAHASAN}

Tabel 2 menunjukkan hasil pengukuran dimensi tebal sampel sebelum dan sesudah sintering $1200^{\circ} \mathrm{C}$. Berdasarkan persamaan 1,rata-rata ratio penyusutan sebesar $4,6 \%$.

Tabel 2 Data hasil pengukuran dimensi sampel sebelum dan sesudah sintering $1200^{\circ} \mathrm{C}$

\begin{tabular}{|c|c|c|}
\hline$\% \mathbf{C r}$ & $\begin{array}{c}\mathbf{T}_{\mathbf{B}} \\
(\mathbf{m m})\end{array}$ & $\begin{array}{c}\mathbf{T}_{\mathbf{A}} \\
(\mathbf{m m})\end{array}$ \\
\hline 0 & 6,30 & 6,01 \\
\hline 0.5 & 6,29 & 6,03 \\
\hline 1 & 6,28 & 6,02 \\
\hline 1.5 & 6,28 & 6,01 \\
\hline 2 & 6,30 & 6,02 \\
\hline
\end{tabular}



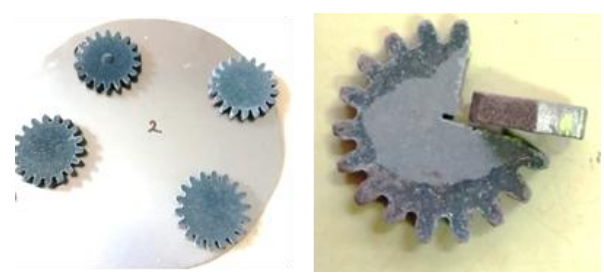

Gambar 4. Sampel roda gigi setelah disintering $1200^{\circ} \mathrm{C}$ (kiri), dan sampel dipotong untuk proses metalografi (kanan).

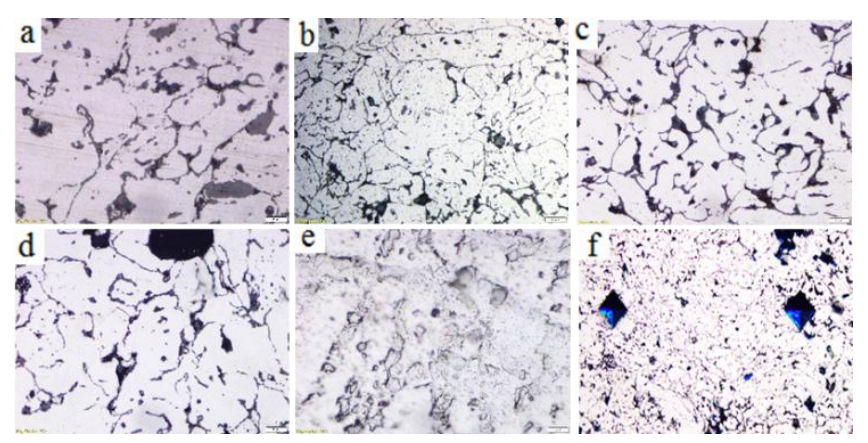

Gambar 5. Penampakan struktur mikro dengan mikroskop optik dengan perbesaran 100x (a) $\mathrm{Cr} 0 \%$; (b)

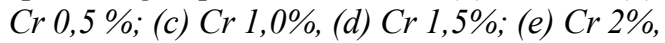
dan (f) Penampakan jejak indentor pada sampel $\mathrm{Cr} 1.5 \%$ dengan beban yang diterapkan sebesar 0,2 kg.

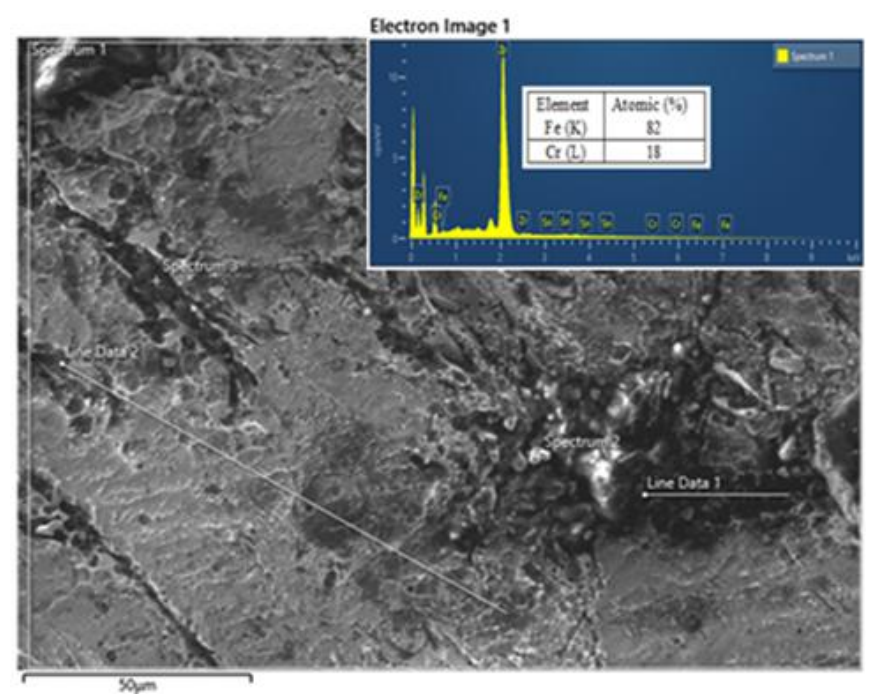

Gambar 6. SEM-EDS dari sampel dengan persentase $\mathrm{Cr}$ $2 \%$.

Seperti terlihat jelas pada gambar 5 pada penampakan struktur mikro pada setiap sampel a-e, terlihat bahwa fasa yang terbentuk relatif seragam pada matriks ferit. Hasil SEM-EDS pada gambar 6 membuktikan bahwa unsur $\mathrm{Cr}$ telah berhasil terdistribusi kedalam fasa utama ferit atau Fe. Namun terdapat perbedaan pada saat persentase $\mathrm{Cr}$ sebesar 2\%, kemungkinan terjadi saturasi yang mengakibatkan penumpukkan serbuk $\mathrm{Cr}$ sehingga terbentuk fasa baru yang memunculkan butiran-butiran baru. Hal ini sama dengan yang dilakukan S. Mushtaq (2017) pada penelitiannya [9], dimana dalam hal ini logam Sn menjadi cair dan terlarut cukup banyak pada besi . Sehingga dapat disimpulkan ada batas tertentu didalam penambahan unsur $\mathrm{Cr}$ didalam pembuatan roda gigi yang berbahan dasar serbuk besi. Didalam penelitian ini diperoleh hasil yang titik maksimum yaitu $1.5 \%$.

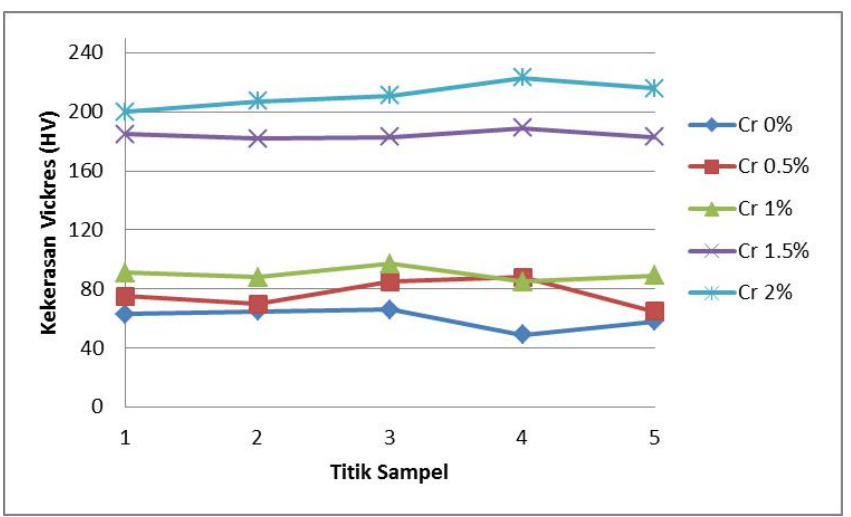

Gambar 7. Grafik hubungan nilai kekerasan tiap sampel dengan variasi doping Cr pada 5 titik uji.

Gambar 7 menunjukkan hasil dari pengujian kekerasan vickres pada 5 titik uji. Diperoleh rata-rata nilai kekerasan vickers. Nilai kekerasan Vickers diperoleh sebesar 60, 77, 90, 184 dan 211 masing-masing untuk doping $\mathrm{Cr}$ sebesar $0,0.5,1,1.5$, dan 2\%. Nilai kekerasan yang diperoleh masih terbilang kecil, hal ini dikarenakan masih terdapat banyak porositas yang ditimbulkan setelah proses sintering. Porositas yang muncul diakibatkan karena proses sintering tidak dilakukan didalam kondisi vakum. Namun demikian pada penelitian sudah dapat memberikan informasi terkait penambahan unsur $\mathrm{Cr}$ memiliki pengaruuh yang signifinikan didalam pembuatan roda gigi lurus berbahan dasar besi, yaitu sifat kekerasan dan perubahan struktur mikronya.

\section{SIMPULAN}

Pembuatan roda gigi lurus berbahan dasar besi dengan menambahkan unsur $\mathrm{Cr}$ telah berhasil dilakukan didalam penelitian ini. Doping $\mathrm{Cr}$ sebesar 0, $0.5,1,1.5$, dan $2 \%$ diterapkan pada pembuatan roda gigi. Air yang berfungsi sebagai binder ditambahan dengan ratio 1:15 selanjutnya sampel dikompaksi sebesar 15 ton dan diteruskan dengan disintering pada suhu $1200{ }^{\circ} \mathrm{C}$ selama 1 jam. Diperoleh hasil ratio penyusutan terhadap perlakuan sintering dengan rata-rata sebesar $4.6 \%$. Dari penampakan struktur mikro disimpulkan bahwa persentase $1.5 \% \mathrm{Cr}$ adalah titik maksimum untuk ditambahkan pada serbuk besi. 
Beban $0.2 \mathrm{~kg}$ diterapkan pada pengujian kekerasan Vickers. Nilai kekerasan Vickers diperoleh sebesar 60, 77, 90, 184 dan 211 masing-masing untuk doping $\mathrm{Cr}$ sebesar $0,0.5,1,1.5$, dan 2\%. Dari data tersebut didapat bahwa penambahan unsur $\mathrm{Cr}$ dapat meningkatkan sifat kekerasan pada roda gigi besi. Nilai kekerasan yang ditunjukkan masih terlalu kecil hal ini disebabkan oleh masih banyak porositas yang ditimbulkan pada proses sintering karena tidak dalam kondisi vakum.

\section{KEPUSTAKAAN}

[1] Orangeleaf Sysyem Ltd, 2020, Market for Powder Metallurgy Components. https://www.pm-review.com/introduction-t o-powder-metallurgy/markets-for-powdermetallurgy-components/. Diakses tanggal 1 April 2020

[2] De Garmo E P, Black J T and Kohser R A, 2008. Materials \& Process In Manufacturing (USA: Tenth Edition)

[3] Muhammad Safrudin Yafie, Widyastutu Widyastuti, 2014, Pengaruh variasi temperatur sintering dan waktu tahan sintering terhadap densitas dan kekerasan pada $\mathrm{Mmc} \mathrm{W}-\mathrm{Cu}$ melalui proses metalurgi serbuk, No.1, volume 1.
[4] Abdul Syukur Alfauzi, Adhy Purnomo, Bambang Tjahjono, Hariyanto, Nur sa'adah, 2019. Pembuatan Roda Gigi dari Bahan Serbuk Logam Tembaga dan Alumunium dengan Proses Kompaksi, Jurnal Rekayasa Mesin, 14, 121-127

[5] Xinmin Li, Mario Sosa, Martin Andersson, Ulf Olofsson, 2016. A study of the efficiency of spur gears made of powder metallurgy materials - ground versus super-finished surfaces, Tribology International, volume 95, pp.211-220.

[6] Malkoc, E., Hazard, J., dan Mater, 2007. Removal of Cromium $(\mathrm{Cr})$ from Wastewater. Arabian Journal. pp 142-219.

[7] Zulkarnain MI, Nopiandi R, 2013. Rancang Bangun Cetakan Roda Gigi Lurus Berbasis Metalurgi Serbuk Tanpa Lubang Poros. Bandung.

[8] Groover M P, 2010. Fundamental of Modern Manufacturing, (USA: 4th Edition)

[9] S. Mushtaq, M.F. Wani, 2017, The study of microhardness of powder metallurgy fabricated $\mathrm{Fe}-\mathrm{Cu}$ alloy using vickers indenter, Advanced Materials Proceedings, 2(4), 259-263 